\title{
Azithromycin Attenuates Pulmonary Inflammation and Emphysema in Smoking-Induced COPD Model in Rats
}

\author{
Yu-feng Wan MD, Zu-hu Huang MSc, Ke Jing PhD, Jun Li PhD, Yi Wang MSc, \\ Chuan-qin $\mathrm{Xu} \mathrm{MSc}$, Jian-hui Chen $\mathrm{PhD}$, and Yu-long Zheng
}

\begin{abstract}
INTRODUCTION: The role of inflammation and immunity in COPD treatment is increasingly being recognized. The relationship between anti-inflammation/immunoregulation and emphysema in COPD lungs remains to be elucidated. The aim of this study was to investigate the effects of azithromycin (Azm) on the development of emphysema in smoking-induced COPD in rats. METHODS: Sprague-Dawley rats $(n=50)$ were randomly assigned to normal, COPD, salinetreated, Azm-treated, and levofloxacin-treated (Lev) groups. The effects of treatment were assessed by measuring the levels of vascular endothelial growth factor (VEGF) by enzyme-linked immunosorbent assay and measuring the numbers of neutrophil and macrophage in bronchoalveolar lavage fluid, vascular endothelial growth factor (VEGF) and VEGF receptor-2 (VEGFR2) protein expression by western blotting. Lung function measurements and histopathological evaluations (mean linear intercept and destructive index) were performed. RESULTS: FEV $_{0.3} /$ FVC $_{\text {and peak }}$ expiratory flow were lower in the COPD group than in the normal group. Mean linear intercept and destructive index were lower in the Azm-treated group than in the COPD, saline-treated, and Lev-treated groups. The numbers of neutrophil and macrophage in bronchoalveolar lavage fluid were lower in the Azm-treated group than in the COPD, saline-treated, and Lev-treated groups. As confirmed by western blotting, the levels of VEGF in lung homogenates were higher in the Azmtreated group than in the COPD, saline-treated, and Lev-treated groups. VEGFR2 protein expression was higher in the Azm-treated group than in the COPD, saline-treated, and Lev-treated groups. CONCLUSIONS: Azm attenuates pulmonary emphysema by partly reversing the decrease in the numbers of inflammatory cells (neutrophil and macrophage) and VEGF secretion and VEGFR2 protein expression in smoking-induced COPD in rats. Key words: chronic obstructive pulmonary disease; emphysema; VEGF; azithromycin; cigarette smoking. [Respir Care 2015;60(1):128-134. @ 2015 Daedalus Enterprises]
\end{abstract}

\section{Introduction}

COPD is currently listed as the fourth leading cause of death in the world and affects more than 200 million people worldwide. It is also an important cause of chronic

\footnotetext{
Drs Wan, Jing, and Li and Mr Huang are affiliated with the Department of Infectious Diseases, First Affiliated Hospital of Nanjing Medical University, Nanjing 210029, People's Republic of China. Drs Wan and Chen, Ms Wang, Ms Xu, and Mr Zheng are affiliated with the Department of Respiratory Diseases, Affiliated Huai'an Hospital of Xuzhou Medical College, Huaian 223002, People's Republic of China.
}

This research was supported by grant ha2012007 from the Huaian Science Fund. disability and permanent impairment, representing a major economic and social burden worldwide ${ }^{1,2}$. Although cigarette smoking is a common etiologic factor, other injurious stimuli also contribute to the deterioration of airway function. Chronic exposure to cigarette smoke (CS) leads to lung inflammation with an increase of inflammatory cells

\footnotetext{
The authors have disclosed no conflicts of interest.

Correspondence: Zu-hu Huang MD PhD, Department of Infectious Diseases, First Affiliated Hospital of Nanjing Medical University, Nanjing 210029, People's Republic of China. E-mail: huangzh@jswst.gov.cn.
}

DOI: $10.4187 /$ respcare. 03344 
such as macrophages,${ }^{3}$ neutrophils,,${ }^{4,5}$ dendritic cells, ${ }^{6,7}$ and $\mathrm{CD} 8^{+}$T lymphocytes. ${ }^{8}$ Release of elastase from these cells, as well as their production of reactive oxygen species, have long been considered to play important roles in disease development. Degradation of extracellular matrix components within alveolar walls by these proteases leads to the development of emphysema, the main characteristic of COPD. ${ }^{9}$

Macrolide antibiotics have immunomodulatory, antiinflammatory, and antibacterial effects. ${ }^{10}$ Actions observed with macrolides include inhibition of neutrophil accumulation, chemokine and cytokine production, as well as inhibition of adhesion molecule expression. Such effects account, at least partially, for the essential role of macrolide antibacterials in the treatment of patients with diffuse panbronchiolitis, bronchiolitis obliterans syndrome, and bronchiectasis. ${ }^{11-13}$ Beneficial clinical effects have also been observed in patients with chronic sinusitis, asthma, and COPD. ${ }^{14-16}$ Long-term azithromycin (Azm) therapy was associated with significant reductions in the rate of exacerbations compared with placebo. ${ }^{17,18}$ However, the mechanism of the anti-inflammatory/immunomodulatory actions of macrolides remains unclear. There are few reports on the role of Azm in the treatment of CS-induced COPD in rats. The aim of this study was to investigate whether oral administration of azithromycin has any effect on the development of smoking-induced COPD in rats, in terms of lung function, bronchoalveolar lavage fluid, and morphometry.

\section{Methods}

\section{Animals}

Fifty male Sprague-Dawley rats, each weighing 192-243 g, were purchased from the Animal Centre of Yangzhou University, Yangzhou, China. The rats were randomly assigned to 5 groups of 10: normal, COPD, saline-treated, Azm-treated, and levofloxacin (Lev)-treated groups. The last 4 groups were exposed to smoke from 20 commercial unfiltered cigarettes (Dafengshou, Jiangsu Cigarette Factory, Huaian, Jiangsu, China) for $1 \mathrm{~h}$ each day, $7 \mathrm{~d}$ a week, for a total of $90 \mathrm{~d}$. The smoke exposure box was $70 \times 50 \times 40 \mathrm{~cm}$. Rats in the Azm-treated group were administered intragastrically with Azm (Pfizer, New York, New York; $50 \mathrm{mg} / \mathrm{kg}$, once/day), and rats in the Lev-treated group were lavaged with Lev (Yangzijiang Pharmaceutical, Taizhou, China; $50 \mathrm{mg} / \mathrm{kg}$, once/d), while rats in the saline-treated group were instilled with saline solution after $30 \mathrm{~d}$ of smoking exposure. One rat in the COPD group died on d 55. Two rats in the Azm-treated group died on d 36 and 44, and 1 rat in the Lev-treated group died on $\mathrm{d} 75$. The lungs of the 4 dead rats were filled with fluid. Instillation of reagent solutions into the lungs

\section{QUICK LOOK}

\section{Current knowledge}

COPD is the fourth leading cause of death in the world and an important cause of chronic disability, representing a major economic and social burden worldwide. Chronic inflammation in COPD is increasingly recognized as a major factor in disease burden.

\section{What this paper contributes to our knowledge}

In an animal model of smoking-induced COPD, azithromycin attenuated pulmonary emphysema by reversing the decrease in the numbers of inflammatory cells and vascular endothelial growth factor secretion. Vascular endothelial growth factor receptor-2 protein expression was elevated in animals treated with azithromycin.

may have resulted in the deaths of 4 rats. Experiments were approved by the animal ethics committee and were performed under strict government and international guidelines.

\section{Pulmonary Function}

Rats from all groups were randomly selected for lung function measurements (PFT, Buxco Research Systems, Wilmington, North Carolina). After induction of anesthesia by intraperitoneal administration of chloral hydrate (3 $\mathrm{mL} / \mathrm{kg}$ ), a Y-type endotracheal cannula was connected to a flow transducer (HX200, Beijing Baianji Corporation, Beijing, China) for measurement of $\mathrm{FEV}_{0.3} / \mathrm{FVC}$ and peak expiratory flow (PEF).

\section{Preparation of Bronchoalveolar Lavage Fluid and Lung Tissue}

Twenty-four $\mathrm{h}$ after the last smoke exposure, rats were weighed and sacrificed with an overdose of pentobarbital, and a tracheal cannula was inserted. Three $\mathrm{mL}$ of sterile phosphate-buffered saline, free of ionized calcium and magnesium but supplemented with $0.05 \mathrm{mM}$ sodium ethylenediaminetetraacetic acid, was instilled 3 times via the tracheal cannula and recovered by gentle manual aspiration. The 3 lavage fractions were centrifuged $(2,000 \mathrm{~g}, 10 \mathrm{~min})$, and the cell-free supernatants were stored at $-70^{\circ} \mathrm{C}$ for subsequent cytokine analysis. The cell pellet was washed twice and finally resuspended in $1 \mathrm{~mL}$ of phosphatebuffered saline. A total cell count was performed in a Bürcker chamber, and the differential cell counts (at least 
400 cells) were performed on cytocentrifuged preparations using standard morphologic criteria after Giemsa staining.

The chest was opened, and the cardiopulmonary block was quickly isolated and excised. The right main bronchus was cross-clamped, and the left lung was filled with $0.5 \%$ low melting agarose in $10 \%$ formalin at a constant pressure of $25 \mathrm{~cm} \mathrm{H}_{2} \mathrm{O}$, allowing for homogenous and full expansion of the lung parenchyma. ${ }^{19}$ The lungs were then fixed in $10 \%$ formalin for $48 \mathrm{~h}$ and paraffin-embedded. Tissue sections from upper and lower lobes of the left lung were used for histological analysis.

\section{Vascular Endothelial Growth Factor Determination}

Vascular endothelial growth factor (VEGF) levels in bronchoalveolar lavage (BAL) fluid supernatants were measured by sandwich enzyme-linked immunosorbent assay using specific anti-mouse monoclonal antibody for capture and detection (R\&D Systems, Minneapolis, Minnesota). Assays were performed according to the manufacturer's protocol.

\section{Western Blotting}

Twenty $\mu \mathrm{g}$ of protein from lung homogenate lysates were electrophoresed and separated on 4-12\% SDS-PAGE and transferred onto nitrocellulose membranes (Bio-Rad, Hercules, California). The membranes were blocked with $5 \%$ skim milk at room temperature for $1 \mathrm{~h}$, and then incubated overnight at $4^{\circ} \mathrm{C}$ with primary antibodies including mouse VEGF receptor (VEGFR) monoclonal IgG, rabbit polyclonal VEGF IgG, goat anti-rabbit antibody, and goat anti-mouse antibody (all from Santa Cruz Biotechnology, Santa Cruz, California). Membranes were reprobed for $\beta$-actin (Santa Cruz Biotechnology) to confirm equal protein loading and transfer. The experiments were performed with at least 5 animals per study group.

\section{Quantification of Emphysema}

Emphysema is a structural disorder characterized by destruction of the alveolar walls and enlargement of the alveolar spaces. We determined destruction of alveolar walls by measuring the destructive index (DI) ${ }^{20}$ and enlargement of alveolar spaces by quantifying the mean linear intercept $(\mathrm{Lm})^{21}$ in air- and CS-exposed rats, as described previously. ${ }^{22}$

Quantification of air space enlargement was determined after 90-day air or CS exposure by measuring the $\mathrm{Lm}$ using image analysis software (ImageJ 1.47, National Institutes of Health, Bethesda, Maryland). Only sections without cutting artifacts, compression, or hilar structures (airway or blood vessel with a diameter larger than $50 \mu \mathrm{m}$ ) were used in the analysis. The Lm was measured by plac- ing a $100 \times 100 \mu \mathrm{m}$ grid over each field. The total length of each line of the grid divided by the number of alveolar intercepts gives the average distance between alveolated surfaces, or the Lm. ${ }^{21}$

The destruction of alveolar walls was quantified by the DI. ${ }^{20}$ A grid with 42 points that were at the center of hairline crosses was superimposed on the lung field. Structures lying under these points were classified as normal (N) or destroyed (D) alveolar and/or duct spaces. Points falling over other structures, such as duct walls and alveolar walls, were not included in the calculations. The DI was calculated from the formula: $D I=D /(D+N) \times 100$.

\section{Statistical Analysis}

Continuous data were expressed as mean $\pm \mathrm{SD}$. Differences were evaluated for statistical significance by analysis of variance using the Kruskal-Wallis test. A $P$ value $<.05$ was considered statistically significant. All analyses were performed using the statistical software SPSS 16.0 (SPSS, Chicago, Illinois).

\section{Results}

\section{Lung Function}

Half of the rats from all groups were randomly selected for lung function measurements. The levels of $\mathrm{FEV}_{0.3} / \mathrm{FVC}$ and PEF were lower in the COPD group compared with the normal and Azm-treated groups $(P<.05) . \mathrm{FEV}_{0.3} / \mathrm{FVC}$ and PEF were higher in the Azmtreated group compared with the saline- and Lev-treated groups $(P<.05)$ (Table 1$)$.

\section{Determination of Relative Cell Number in Bronchoalveolar Lavage Fluid}

An increase in the numbers of neutrophil and macrophage in airways (BAL fluid) was observed in the COPD group compared with those in the normal group. As expected, the numbers of neutrophil and macrophage in Azmtreated group were significantly decreased compared with those in the COPD, saline-treated, and Lev-treated groups (Table 2).

\section{Vascular Endothelial Growth Factor Determination}

The levels of VEGF in BAL fluid were lower in the COPD group $(855 \pm 150 \mathrm{pg} / \mathrm{mL})$ than in the normal group $(1,568 \pm 276 \mathrm{pg} / \mathrm{mL})$ or the Azm-treated group $(1,093 \pm 192 \mathrm{pg} / \mathrm{mL})(P<.05)$. There were also significant differences of VEGF levels in BAL fluid in the Azmtreated group compared with those of the Lev-treated group 
Table 1. Comparison of Lung Function Parameters in the 5 Groups of Rats

\begin{tabular}{lccc}
\hline \hline & $n$ & $\mathrm{FEV}_{0.3} / \mathrm{FVC} \%$ & $\mathrm{PEF} \mathrm{mL/s}$ \\
\hline Normal & 5 & $85.3 \pm 5.2$ & $46.8 \pm 5.9$ \\
COPD & 4 & $63.5 \pm 6.1^{* \dagger}$ & $18.1 \pm 2.7^{* \dagger}$ \\
Saline-treated & 5 & $64.3 \pm 6.4^{*}$ & $19.0 \pm 3.2^{* \dagger}$ \\
Azm-treated & 4 & $75.3 \pm 5.7^{*}$ & $34.1 \pm 5.5^{*}$ \\
LeV-treated & 5 & $65.0 \pm 4.7^{*}$ & $21.4 \pm 5.6^{*} \dagger$ \\
& & & \\
Values are mean \pm SD. & & \\
$* P<.05$ compared with normal group. \\
$\dagger P<.05$ compared with azithromycin (Azm)-treated group. \\
Lev = levofloxacin \\
\end{tabular}

Table 2. Comparison of Neutrophil and Macrophage Cells in BAL Fluid of the 5 Groups of Rats

\begin{tabular}{lrcc}
\hline \hline & $n$ & Neutrophil & Macrophages \\
\hline Normal & 10 & $17.6 \pm 3.34$ & $150.5 \pm 17.7$ \\
COPD & 9 & $174.4 \pm 21.5^{* \dagger}$ & $81.1 \pm 15.8^{*}$ \\
Saline-treated & 10 & $169.5 \pm 25.0^{* \dagger}$ & $81.0 \pm 16.1^{*}$ \\
Azm-treated & 8 & $135.6 \pm 24.4^{*}$ & $95.0 \pm 16.6^{*}$ \\
Lev-treated & 9 & $172.0 \pm 18.6^{* \dagger}$ & $81.7 \pm 14.5^{*}$ \\
& & \\
Values are mean \pm SD. & & \\
$* P<.05$ compared with normal group. \\
$\dagger P<.05$ compared with azithromycin (Azm)-treated group. \\
Lev = levofloxacin \\
\end{tabular}

$(875 \pm 169 \mathrm{pg} / \mathrm{mL})(P<.05)$ and saline-treated group $(864 \pm 166 \mathrm{pg} / \mathrm{mL})(P<.05)$.

\section{Western Blotting}

VEGF and VEGFR2 protein expression was analyzed by western blotting in lung homogenates from rats in the 5 experimental groups (Fig. 1). Significant decreases were observed in VEGF and VEGFR2 expression in the COPD group and the saline- and Lev-treated groups compared with the normal group. Treatment with Azm led to an increase in lung VEGF and VEGFR2 protein expression compared with the COPD, saline-treated, and Lev-treated groups.

\section{Quantification of Emphysema}

Pulmonary emphysema is characterized by destruction of alveolar walls due to damage to the lung parenchyma, leading to enlargement of alveolar spaces. Therefore, to quantify emphysematous lesions, it is recommended to evaluate both the air space enlargement (quantified by the

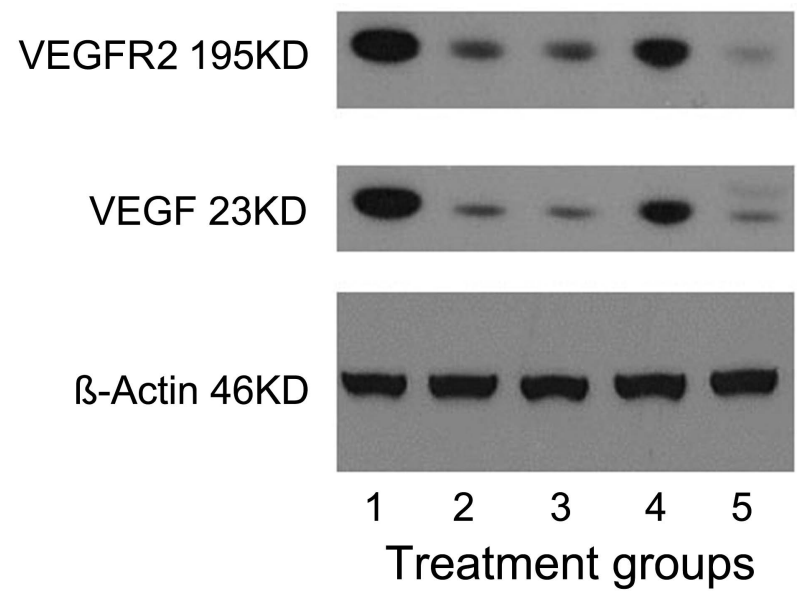

Fig. 1. Western blot analysis of vascular endothelial growth factor (VEGF) and vascular endothelial growth factor receptor-2 (VEGFR2) protein expression in lung homogenates from the 5 groups of rats.

measurement of the Lm) and the destruction of the alveolar walls (quantified by the measurement of the DI). ${ }^{20,21}$

Chronic CS exposure clearly induced pulmonary emphysema in SD rats, evidenced by a significant increase in $\mathrm{Lm}$ (air, $43.32 \pm 4.78 \mu \mathrm{m}$ vs cigarette smoke, $77.8 \pm 14.76 \mu \mathrm{m}, P=.00$ ) and DI (air, $17.23 \pm 5.60 \mathrm{vs}$ smoke, $56.40 \pm 8.41, P=.00$ ). Furthermore, the $\mathrm{Lm}$ and DI of the chronic CS exposure with azithromycin-treated rats were significantly higher than the air-exposed rats $(P=.00)$. However, in azithromycin-treated animals with chronic CS exposure, the induction of emphysema, evidenced by a significant decrease in Lm (Azm-treated, $57.98 \pm 10.12 \mu \mathrm{m}$ vs saline-treated, $75.28 \pm 10.30 \mu \mathrm{m}$, $P=.01 ;$ and vs Lev-treated, $75.39 \pm 10.99 \mu \mathrm{m}, P=.01)$ and DI (Azm-treated, $46.58 \pm 7.44$ vs saline-treated, $55.05 \pm 7.02, P=.03$; and vs Lev-treated, $55.1 \pm 6.94$, $P=.04)$, indicating a partial protection against pulmonary emphysema in the Azm-treated rats (Fig. 2, A and B). The significant air space enlargement due to chronic CS exposure and the attenuated emphysema in chronic CS exposure with Azm-treated rats is illustrated with H\&E-stained lung tissue sections (Fig. 3).

\section{Discussion}

COPD is mainly caused by cigarette smoking, and is characterized by pulmonary emphysema and inflammation with an increase of inflammatory cells of both the innate and the adaptive immune system. In this study, chronic exposure to CS resulted in a substantial accumulation of inflammatory cells in the airways of the rats. However, the CS-induced neutrophils and macrophages in the BAL fluid were significantly decreased in the Azm-treated rats, compared with COPD littermates. A significant increase of VEGF level was observed in the serum and lung 

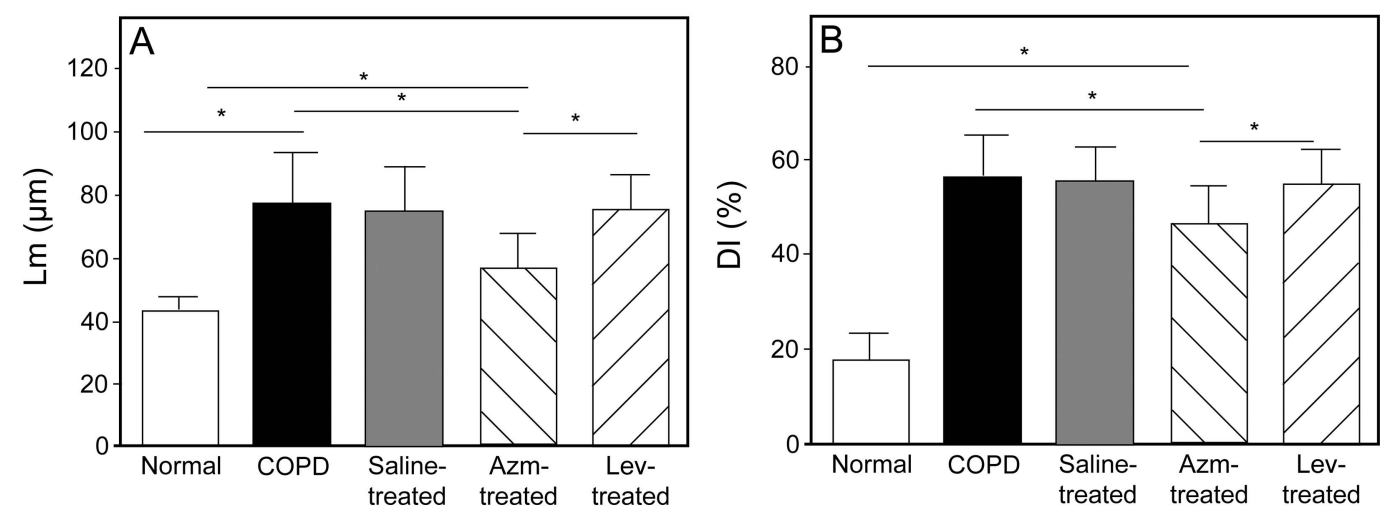

Fig. 2. Quantification of pulmonary emphysema in the 5 groups of rats. A, mean linear intercept $(\mu \mathrm{m})$; $B$, destructive index $\left({ }^{\star} P<.05\right)$. $\mathrm{Lm}=$ mean linear intercept; $\mathrm{DI}=$ destructive index .
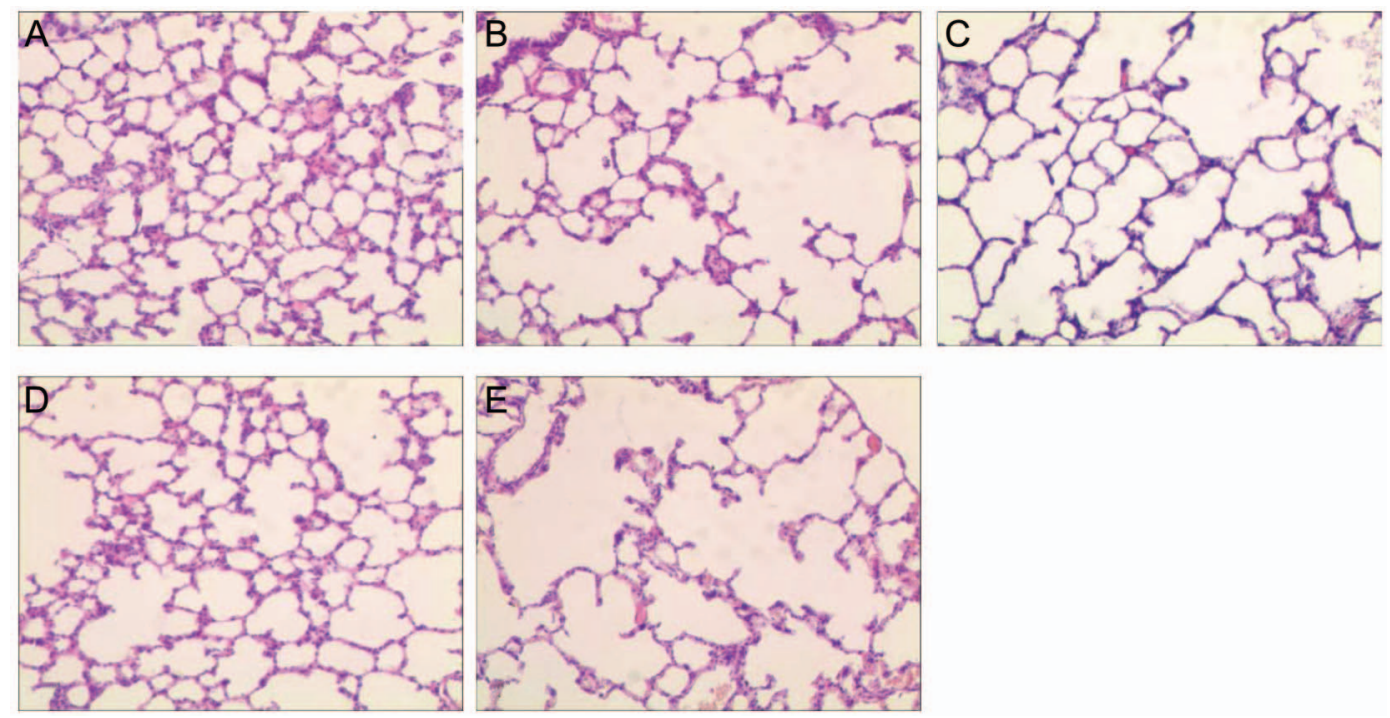

Fig. 3. Hematoxylin and eosin staining of lung tissue sections from rats. A, normal group; B, COPD group; C, saline-treated group; D, azithromycin-treated group; E, levofloxacin-treated group (magnification $\times 100$ ).

homogenates of azithromycin-treated rats, compared with the COPD, saline-treated, and Lev-treated groups. The exposure to CS resulted in development of pulmonary emphysema in model littermates. A partial protection against pulmonary emphysema was discovered in the Azm-treated rats. In contrast, levofloxacin had no effect on the development of airway wall remodeling and airway inflammation.

COPD is characterized by an accelerated decline in lung function, expressed as the $\mathrm{FEV}_{1}$ and its ratio to the FVC, namely $\mathrm{FEV}_{1} / \mathrm{FVC}$. The present study showed that exposure of rats to cigarette smoking decreased $\mathrm{FEV}_{0.3} / \mathrm{FVC}$ and PEF, which is similar to clinical observations in patients with COPD. COPD is characterized by air flow limitation that is not fully reversible due to airway inflammation and changes of airway anatomy. Airway remodeling in COPD consists of several structural changes like changes in bronchial epithelium, bronchial glands hypertrophy, and smooth muscle hyperplasia and hypertrophy. Those changes are related to an increase in various cytokines, mucus-containing cell number, and proteolytic burden in animal models of cigarette smoke exposure ${ }^{23-25}$ and in COPD. ${ }^{26}$ In this study, the Azm-treated group showed greater attenuation of emphysema than the COPD group, and $\mathrm{FEV}_{0.3} / \mathrm{FVC}$ and PEF were higher in the Azm-treated group than in the COPD group but lower than those of the normal group. Therefore, azithromycin can partially improve lung function and attenuate emphysematous changes in COPD rats.

Investigations in our experimental findings presented here with the use of cell counts show that azithromycin treatment efficiently reduced neutrophil and macrophage numbers in bronchoalveolar lavage fluid. Neutrophils and macrophages have an important role in the pathogenesis of 


\section{Azithromycin and Inflammation in Rats With SMOKing-InduCED COPD}

airway inflammation in COPD. Activated neutrophils and macrophages cause lung destruction through the release of oxygen radicals and proteolytic enzymes such as neutrophil elastase and matrix metalloproteinases, including matrix metalloproteinases 8,9 , and 12 (formerly called macrophage elastase). ${ }^{27}$ Neutrophil elastase-induced production of mucin occurs via proteolytic cleavage of transforming growth factor $\alpha$, a ligand of epidermal growth factor receptor. Excessive mucus production and impaired mucociliary clearance contribute to airway obstruction in patients with COPD. ${ }^{28}$ In addition, neutrophil and macrophages can release cytokines and chemokines, which can potentiate inflammation and trigger an immune response. ${ }^{29}$

We have shown in the present study that cigarette smoke reduces VEGF expression in a lung model of smoking in rats. VEGF, which is highly expressed in the normal lung, plays a critical role in lung development and the maintenance of alveolar structure in the adult lung. ${ }^{30}$ VEGF expression is decreased in emphysematous lungs concomitant with increased endothelial cell apoptosis, and the inhibition of VEGFRs leads to the development of emphysema-like changes in the lung. ${ }^{31}$ VEGF levels are also reduced in the bronchoalveolar lavage fluid of smokers. ${ }^{32}$ Interestingly, VEGFR inhibition leads to the enlargement of the air spaces, increased endothelial cell death, and decreased capillary density, characteristic of emphysema. ${ }^{30,33}$ The comparison of the expressions of VEGF and VEGFR2 protein in the samples from rats with and without emphysema demonstrated that samples from emphysematous lungs contained a lower amount of the growth factor and its receptor. In addition, the levels of VEGF in BAL fluid of the Azm-treated group were lower than those of the normal group but higher than those of the COPD group. The results above suggest that azithromycin can partially reverse the cigarette smoke-induced decrease of VEGF and VEGFR2 expression.

\section{Conclusions}

We have demonstrated that azithromycin leads to beneficial VEGF expression and a decreased number of neutrophils and macrophages upon CS exposure, which is reflected in a partial protection against the development of pulmonary emphysema. In addition, the difference in the inhibitory profile of azithromycin from levofloxacin highlights the potential of the azithromycin scaffold for the development of new or combination therapies for COPD.

\section{ACKNOWLEDGMENTS}

We thank Greet Yang Shen, Yao-wu Li, Hong Li, Hong-yan Niu, Ya-ping Han, and Song Chen for their technical assistance.

\section{REFERENCES}

1. Lopez AD, Mathers CD, Ezzati M, Jamison DT, Murray CJ. Global and regional burden of disease and risk factors, 2001: systematic analysis of population health data. Lancet 2006;367(9524):17471757

2. Mannino DM. Chronic obstructive pulmonary disease: definition and epidemiology. Respir Care 2003;48(12):1185-1191; discussion 1191-1193.

3. Shapiro SD. The macrophage in chronic obstructive pulmonary disease. Am J Respir Crit Care Med 1999;160(5 Pt 2):S29-S32.

4. Lacoste JY, Bousquet J, Chanez P, Van Vyve T, Simony-Lafontaine $\mathrm{J}$, Lequeu $\mathrm{N}$, et al. Eosinophilic and neutrophilic inflammation in asthma, chronic bronchitis, and chronic obstructive pulmonary disease. J Allergy Clin Immunol 1993;92(4):537-548.

5. Tashkin DP. Is it asthma, COPD, or something in between, and does it matter? Respir Care 2012;57(8):1354-1356.

6. Casolaro MA, Bernaudin JF, Saltini C, Ferrans VJ, Crystal RG. Accumulation of Langerhans' cells on the epithelial surface of the lower respiratory tract in normal subjects in association with cigarette smoking. Am Rev Respir Dis 1988;137(2):406-411.

7. Soler P, Moreau A, Basset F, Hance AJ. Cigarette smoking-induced changes in the number and differentiated state of pulmonary dendritic cells/Langerhans cells. Am Rev Respir Dis 1989;139(5):11121117.

8. O'Shaughnessy TC, Ansari TW, Barnes NC, Jeffery PK. Inflammation in bronchial biopsies of subjects with chronic bronchitis: inverse relationship of CD8 + T lymphocytes with FEV1. Am J Respir Crit Care Med 1997;155(3):852-857.

9. Barnes PJ. Immunology of asthma and chronic obstructive pulmonary disease. Nat Rev Immunol 2008;8(3):183-192.

10. Martinez FJ, Curtis JL, Albert R. Role of macrolide therapy in chronic obstructive pulmonary disease. Int $\mathrm{J}$ Chron Obstruct Pulmon Dis 2008;3(3):331-350.

11. Azuma A, Kudoh S. Diffuse panbronchiolitis in East Asia. Respirology 2006;11(3):249-261.

12. Vanaudenaerde BM, Meyts I, Vos R, Geudens N, De Wever W, Verbeken EK, et al. A dichotomy in bronchiolitis obliterans syndrome after lung transplantation revealed by azithromycin therapy. Eur Respir J 2008;32(4):832-843.

13. Altenburg J, de Graaff CS, Stienstra Y, Sloos JH, van Haren EH, Koppers RJ, et al. Effect of azithromycin maintenance treatment on infectious exacerbations among patients with non-cystic fibrosis bronchiectasis: the BAT randomized controlled trial. J Am Med Assoc 2013;309(12):1251-1259.

14. Gotfried MH. Macrolides for the treatment of chronic sinusitis, asthma, and COPD. Chest 2004;125(2 Suppl):52S-60S; quiz 60S-61S.

15. Hahn DL. Macrolide therapy in asthma: limited treatment, long-term improvement. Eur Respir J 2009;33(5):1239.

16. Yamaya M, Azuma A, Takizawa H, Kadota J, Tamaoki J, Kudoh S. Macrolide effects on the prevention of COPD exacerbations. Eur Respir J 2012;40(2):485-494.

17. Blasi F, Bonardi D, Aliberti S, Tarsia P, Confalonieri M, Amir O, et al. Long-term azithromycin use in patients with chronic obstructive pulmonary disease and tracheostomy. Pulm Pharmacol Ther 2010;23(3):200-207.

18. Albert RK, Connett J, Bailey WC, Casaburi R, Cooper JA Jr, Criner GJ, et al. Azithromycin for prevention of exacerbations of COPD. N Engl J Med 2011;365(8):689-698.

19. Halbower AC, Mason RJ, Abman SH, Tuder RM. Agarose infiltration improves morphology of cryostat sections of lung. Lab Invest 1994;71(1):149-153.

20. Saetta M, Shiner RJ, Angus GE, Kim WD, Wang NS, King M, et al. Destructive index: a measurement of lung parenchymal destruction in smokers. Am Rev Respir Dis 1985;131(5):764-769.

21. Thurlbeck WM. Measurement of pulmonary emphysema. Am Rev Respir Dis 1967;95(5):752-764. 


\section{AZithromycin and Inflammation in Rats With SMOKING-INDUCED COPD}

22. D'Hulst AI, Vermaelen KY, Brusselle GG, Joos GF, Pauwels RA. Time course of cigarette smoke-induced pulmonary inflammation in mice. Eur Respir J 2005;26(2):204-213.

23. Takubo Y, Guerassimov A, Ghezzo H, Triantafillopoulos A, Bates $\mathrm{JH}$, Hoidal JR, et al. Alpha1-antitrypsin determines the pattern of emphysema and function in tobacco smoke-exposed mice: parallels with human disease. Am J Respir Crit Care Med 2002;166(12 Pt 1): 1596-1603.

24. Ofulue AF, Ko M, Abboud RT. Time course of neutrophil and macrophage elastinolytic activities in cigarette smoke-induced emphysema. Am J Physiol 1998;275(6 Pt 1):L1134-1144.

25. Shapiro SD, Goldstein NM, Houghton AM, Kobayashi DK, Kelley D, Belaaouaj A. Neutrophil elastase contributes to cigarette smokeinduced emphysema in mice. Am J Pathol 2003;163(6):2329-2335.

26. Pelegrino NR, Tanni SE, Amaral RA, Angeleli AY, Correa C, Godoy I. Effects of active smoking on airway and systemic inflammation profiles in patients with chronic obstructive pulmonary disease. Am J Med Sci 2013;345(6):440-445.

27. Chung KF, Adcock IM. Multifaceted mechanisms in COPD: inflammation, immunity, and tissue repair and destruction. Eur Respir $\mathbf{J}$ 2008;31(6):1334-1356
28. Fahy JV, Dickey BF. Airway mucus function and dysfunction. N Engl J Med 2010;363(23):2233-2247.

29. Cazzola M, Page CP, Calzetta L, Matera MG. Emerging antiinflammatory strategies for COPD. Eur Respir J 2012;40(3):724-741.

30. Kasahara Y, Tuder RM, Taraseviciene-Stewart L, Le Cras TD, Abman S, Hirth PK, et al. Inhibition of VEGF receptors causes lung cell apoptosis and emphysema. J Clin Invest 2000;106(11): 1311-1319.

31. Kasahara Y, Tuder RM, Cool CD, Lynch DA, Flores SC, Voelkel NF. Endothelial cell death and decreased expression of vascular endothelial growth factor and vascular endothelial growth factor receptor 2 in emphysema. Am J Respir Crit Care Med 163(3 Pt 1): 737-744, 2001.

32. Koyama S, Sato E, Haniuda M, Numanami H, Nagai S, Izumi T. Decreased level of vascular endothelial growth factor in bronchoalveolar lavage fluid of normal smokers and patients with pulmonary fibrosis. Am J Respir Crit Care Med 2002;166(3):382-385.

33. Tang K, Rossiter HB, Wagner PD, Breen EC. Lung-targeted VEGF inactivation leads to an emphysema phenotype in mice. J Appl Physiol 2004;97(4):1559-1566, discussion 1549. 